\title{
RANCANG BANGUN SISTEM KONTROL PENYIRAM TANAMAN BERDASARKAN SENSOR SOIL MOISTURE DENGAN MENGGUNAKAN ARDUINO
}

\author{
${ }^{1}$ Adhi Cahyono \\ ${ }^{1}$ Program Studi Teknik Informatika - Fakultas Teknik - Universitas Yudharta \\ 1adhi.cahyono@gmail.com
}

\begin{tabular}{l|l|l} 
Received : April, 2019 & Accepted : Mei, 2019 & Published : Juni, 2019
\end{tabular}

\begin{abstract}
In this era of development, technological development encourages people to continue to think creatively to maximize the performance of existing technology to improve human work in daily life. Almost all activities of human activities use modern technology, ranging from the world of industry, households and even agriculture. In the field of agriculture still has problems, one of which is watering the plants that are still manually.

For this reason, it is necessary to think of a plant sprinkler automatically. Where this tool changes the role of humans in the care of plants, namely in terms of watering plants. One of these methods helps human work every day to be more time efficient and practical without having to place it.

With this tool, it is expected that farming activities with plant watering systems will automatically be increasingly in demand. Because this tool is made capable of watering plants automatically based on the value of soil moisture detected by soil moisture sensors. With the control system using Arduino as a microcontroller and also the instructor of the water pump.

Keywords: soil sensor moisture, arduino, microcontroller, water pump

\section{BAB I PENDAHULUAN}

Tanaman merupakan tumbuhan yang di budidayakan agar dapat di ambil manfaatnya. Tanaman sebagai salah satu makhluk hidup yang sangat berguna untuk pemenuhan kebutuhan manusia. Di era pambangunan ini perkembangan teknologi mendorong manusia untuk terus berfikir kreatif, tidak hanya menggali penemuan-penemuan baru, tapi juga memaksimalkan kinerja teknologi yang ada untuk meningkatkan kerja manusia dalam kehidupan sehari-hari. Khususnya komputer sudah demikian majunya, merambah setiap bidang kehidupan. Hampir semua aktifitas kegiatan manusia menggunakan teknologi modern, mulai dari dunia industri, rumah tangga bahkan bidang pertanian.

Dalam bidang pertanian masih memiliki kendala, salah satunya penyiraman air pada tanaman yang masih secara manual. Hal ini berbanding terbalik dengan kemajuan teknologi. Untuk itu perlu difikirkan sebuah alat penyiram tanaman secara otomatis. Dimana alat ini mengganti peran manusia dalam perawatan tanaman yaitu dalam hal penyiram tanaman. Salah satu metode ini membantu kerja manusia dalam setiap harinya agar lebih efisien waktu dan praktis tanpa harus ketempatnya. Pada penelitian Buti Delya, Ahmad Tusi dkk (2014) yang berjudul “ Rancang Bangun Sistem Hidroponik Pasang Surut Otomatis Untuk Budidaya Tanaman Cabai”. Sistem hidroponik pasang surut pada umumnya menggunakan pengatur waktu (timer) untuk proses pemberian nutrisi. Pengguanaan timer memiliki beberapa kekurangan salah satunya adalah pemberian larutan nutrisi yang tidak efisien/boros. Penelitian lainnya yang digunakan untuk penyiraman tanaman otomatis menggunakan sensor soil moisture (sensor kelembaban tanah) yang dilakukan oleh Achmad Dimas Permadi, dkk (2015) Maka penelitian kali ini dikembangkan dengan menambah sensor soil moisture (sensor kelembaban tanah) sebagai dasar pengontrolannya yang berbasis arduino. Dengan alat ini diharapkan kegiatan bercocok tanam semakin diminati.
\end{abstract}

\subsection{Analisis Alat dan Bahan}

\section{BAB II METODE PENELITIAN}

\subsubsection{Kebutuhan Perangkat Lunak}

Perangkat lunak yang dibutuhkan untuk membangun aplikasi ini adalah :

a. Sistem operasi Windows 7 ultimate 32 bit

b. Arduino IDE 1.8.5

c. Script on / off water pump 


\section{d. Script sensor soil moisture}

\subsubsection{Kebutuhan Perangkat Keras}

Perangkat keras yang dibutuhkan untuk membangun aplikasi ini adalah :
a. Komputer/laptop
b. Smartphone android 2.0
c. Arduino
d. Sensor soil moisture YL 69
e. Water pump DC 12 Volt
f. Power Suply 5 Volt
g. Power Suply 12 Volt
h. Relay 5 Volt
i. Kabel Jumper
j. Kabel USB

\subsection{Flow chart}

Adapun flowchart pada penelitian iniadalah sebagai berikut

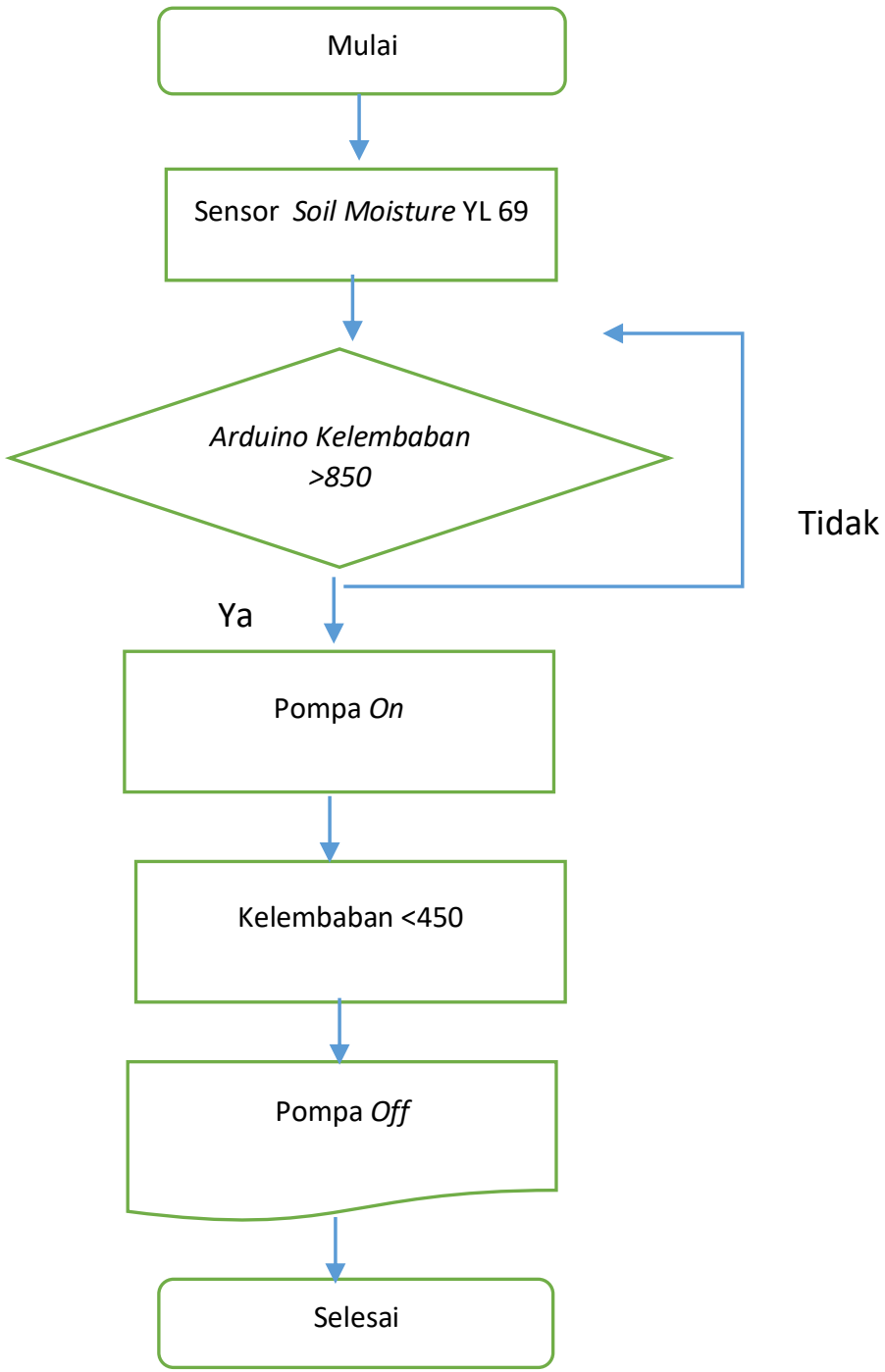

Gambar 2.1 Flow Chart System 


\subsection{Membuat Program Sistem Kontrol}

\section{HASIL UJICOBA DAN PEMBAHASAN}

Sebelum membuat code program untuk sistem kontrol, terlebih dahulu menyusun rangkaian hardwarenya. Agar bisa diketahui program yang telah di buat berjalan atau tidak. Selain Arduino sendiri, terdiri beberapa hardware pendukung lainnya seperti kabel jumper line male to male, male to female, female to female, sensor soil moisture YL69, Relay 5 volt dan Converter AC to DC 12 volt dan 5 volt. Wiring diagramnya terlihat seperti dibawah ini :

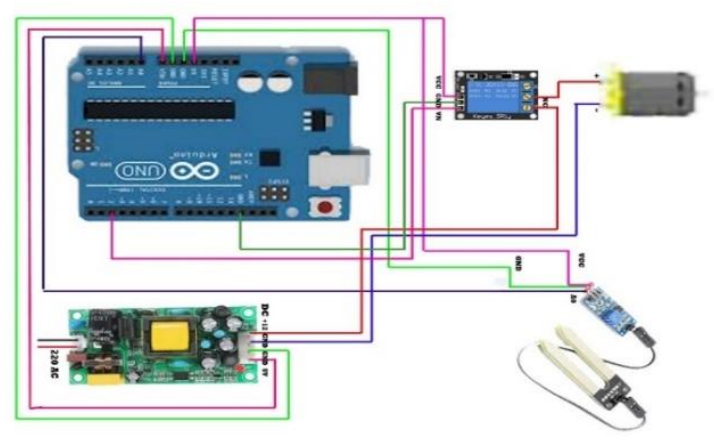

Gambar 3.1 Gambar Skema Rangkaian

\subsection{Code Utama Program}

Sebelum memasukkan Script pada Aplikasi IDE 1.8.5 Arduino, dilakukan dahulu pengecekan USB Arduino apakah sudah tersambung dengan pin pada Laptop. Setelah itu klik dua kali pada icon aplikasi Arduino sampai muncul tampilan seperti dibawah ini :

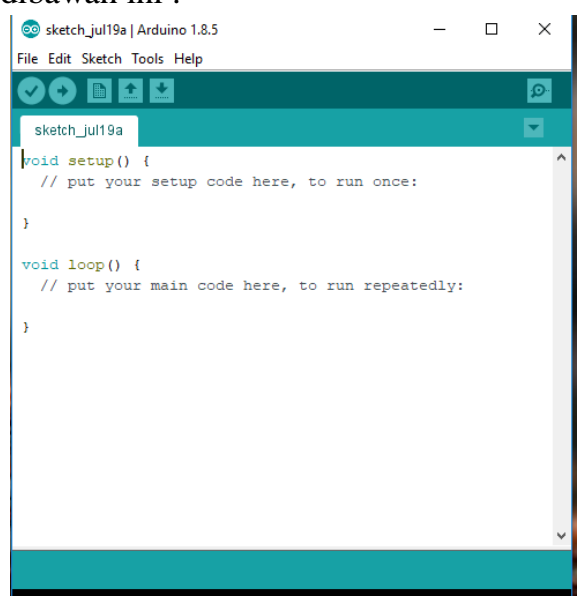

Gambar 3.2 Tampilan Sketch pada aplikasi Arduino

Pastikan memilih Board yang sesuai dengan Arduino. Dengan klik tombol Tools $>$ Board kemudian pilih Board yang sesuai dengan Arduino yang digunakan.

Setelah memilih Board yang sesuai denagn Arduino, pastikan serial port akan digunakan oleh board Arduino sudah benar. Pada menu Tools > Serial Port. Pilih COM8 atau yang lebih tinggi (COM9 dan COM10 sudah direservasi untuk serial port hardware). Untuk mencari tahu, dapat melepaskan koneksi ke board Arduino dan buka kembali menu tadi pilihan yang menghilang harusnya adalah board Arduino. Koneksikan kembali board-nya dan pilih serial port yang sesuai. Kemudian masukkan script dibawah ini : 


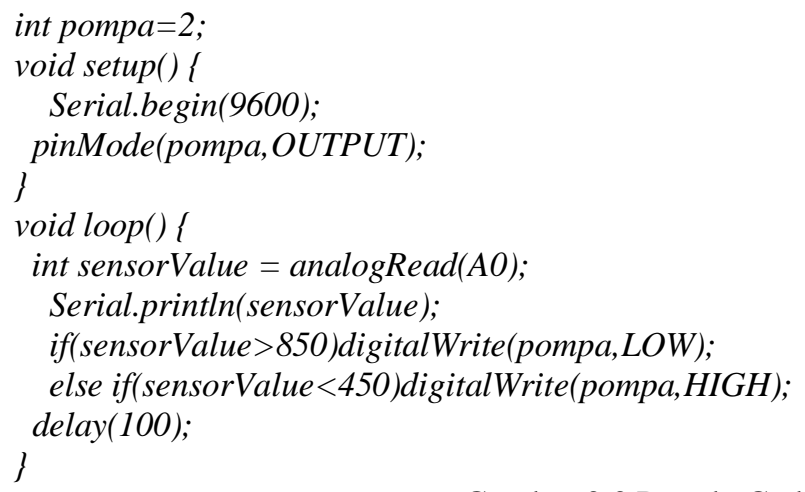

Gambar 3.3 Pseudo Code Upload

Setelah semua script sudah dimasukkan maka tekan atau klik tombol "Upload" pada software. Tunggu beberapa saat lihat led TX dan RX pada board Arduino berkelap-kelip. Bila upload berhasil akan ada pesan "Done uploading" yang muncul pada status bar.

\subsection{Pengujian}

Tahap selanjutnya adalah pengujian system. Pengujian sistem adalah tahap yang sangat penting, pengujian ini bertujuan untuk mengetahui kualitas sistem yang sudah terbuat serta mengetahui kelemahan - kelemahan sistem tersebut. Adapun pengujian yang akan dilakukan pada penelitian ini sebagai berikut :

1. Pengujian Relay

Pada pengujian ini koneksi antara relay dengan arduino dilakukan dengan menggunakan perintah on / off untuk mengetahui relay bekerja atau tidak sebelum komponen hardware dirangkai. Karena fungsi relay pada alat ini sebagai saklar on / off.

\section{Pengujian Sensor Soil Moisture}

Pada pengujian ini sensor dikoneksikan dengan arduino. Sensor akan di tancapkan pada tanah kering dan tanah basah. Dibawah ini adalah pengujian sensor pada tanah kering.

Dari hasil pengujian diatas menunjukkan nilai kelembaban tanah 730.Pengujian yang kedua pada sensor adalah pada tanah basah, gambarnya seperti dibawah ini.

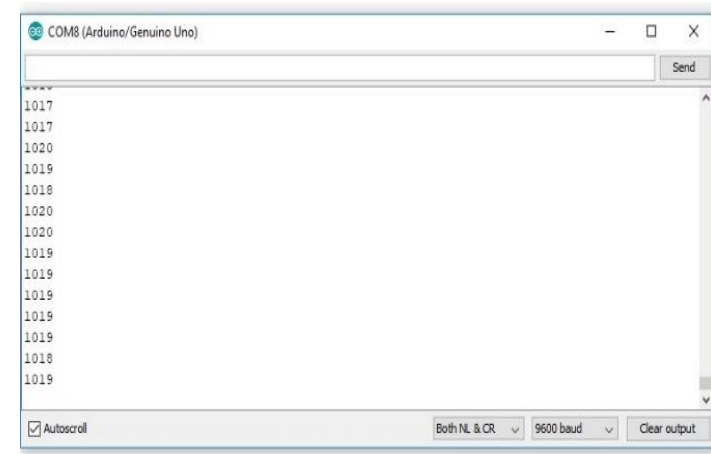

(a)

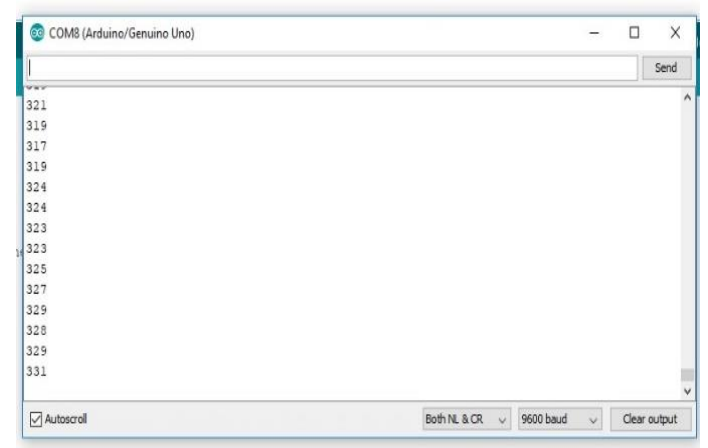

(b)

Gambar 3.4 (a) Nilai Kelembaban pada Tanah Kering, (b) Nilai KelembapanTanah Basah

Dari hasil pengujian di atas menunjukkan nilai kelembaban tanah sebesar 295. Hasil dari 2 pengujian maka ditentukan nilai kelembaban tanah yang akan dimasukkan dalam program, dimana nilai ini menjadi dasar pengontrol sistem penyiraman tanah. Untuk nilai kelembaban tanah kering 850, nilai ini lebih rendah / turun daripada hasil pengujian. Hal ini di karenakan pompa akan on / bekerja jika kelebaban tanah mau kering. Tujuannya untuk menjaga kondisi tanah masih mengandung air agar tanaman tidak sampai mati. Untuk nilai kelembaban tanah basah 450, nilai ini lebih tinggi / 
naik daripada hasil pengujian. Hal ini dikarenakan pompa akan off / mati jika kondisi tanah mau basah. Tujuannya adalah untuk menjaga tanaman agar tidak terendam air.

3. Pengujian rangkaian Sensor, Water pump, dan Arduino.

Pengujian alat ini pertama sensor dikoneksikan dengan arduino. Sedangkan water pump dengan relay ke arduino. Setelah hardware sudah terangkai semua, maka perintah pada skrip dengan memasukkan nilai kelembaban yang berdasarkan pengujian ke 2 ( sensor soil moisture ). Jika nilai kelembaban tanah $>850$ maka water pump akan bekerja atau on dan akan mati atau off secara otomatis jika nilai kelembaban tanah $<450$. Seperti gambar dibawah ini :

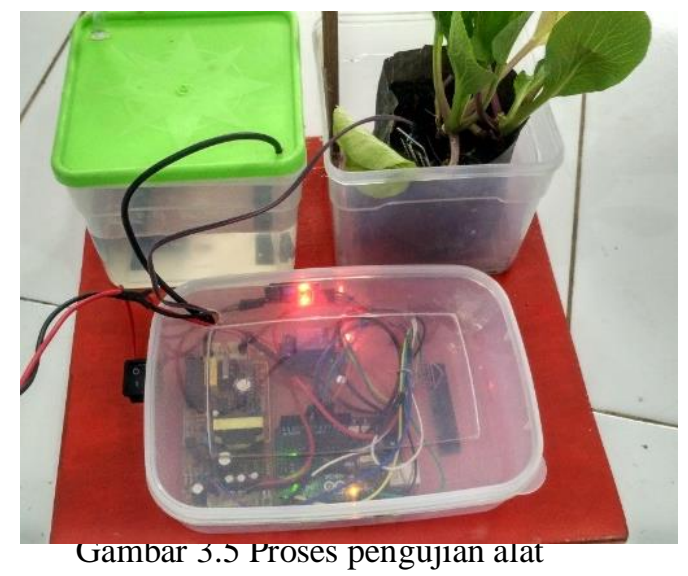

Proses pengujian alat diatas dimana berawal dari sensor soil moisture yang ditancapkan panah tanah akan mendeteksi kelembaban tanah. Setelah mengetahui nilai kelembaban tanah akan ditransfer ke arduino dimana arduino disini sebagai mikrokontroller. Setelah data diproses oleh mikrokontroller maka akan dikirim perintah menuju water pump untuk bisa on / bekerja,melalui relay sebagai saklar on / off. Water pump akan secara otomatis off / mati jika sensor soil moisture mendeteksi batas nilai kelembaban tanah yang sudah ditentukan oleh program.

\subsection{Kesimpulan}

\section{BAB IV KESIMPULAN DAN SARAN}

Berdasarkan hasil pengujian daripada rancang bangun system kontrol penyiram tanaman berdasarkan sensor soil moisture menggunakan arduino dapat disipulkan ssebagai berikut:

1. Sistem Kontrol Penyiram Tanaman yang telah dibuat mampu menyiram tanaman dengan berdasarkan sensor soil moisture dimana prinsip kerjanya berdasarkan nilai kelebaban tanah yang telah dibaca oleh sensor soil moisture. Sehingga water pump secara otomatis on / bekerja sesuai batas nilai kelebaban tanah yang sudah ditentukan pada program.

2. Alat ini memiliki system otomatis mematikan relay sebagai saklar pada saat bekerja tanpa perlu kawatir lupa untuk mematikan relay pada pompa, karena system ini berdasar nilai kelembaban tanah yang dibaca dari sensor soil moisture.

\section{2 Saran}

Pada skripsi ini tentunya masih ada kekurangan yang ditemukan, maka dapat diberi saran untuk dapat dikembangkan lebih lanjut sehingga bisa menjadi lebih sempurna, beberapa pengembangan yang bisa dilakukan diantaranya adalah :

1. Diharapkan alat ini ada notifikasi khusus untuk bisa memudahkan pengguna mengetahui alat ini sudah bekerja ataua tidak.

2. Diharapkan alat ini bisa dikontrol melalui web sehingga memiliki aplikasi sendiri pada Android untuk mengontrol alat ini. 


\section{DAFTAR PUSTAKA}

[1] Achmad Dimas Permadi, Ing.Soewarto Hardhienata dkk.Model Sistem Penyiraman dan Penerangan Taman Mengunakan Soil Moisture Sensor dan RTC(Real Time Clock). Bogor.Universitas Pakuan.

[2] Bayu Aji Kurniawan.2015. Alat Penyiram Tanaman Otomatis Dengan Logika Fuzzy Berbasis ATMegal6.Yogyakarta.Universitas Negeri Yogyakarta.

[3] Bayu Agus Prasetya.2016.Rancang Bangun dan Implementasi Sistem Otomatisasi Penyiraman Tanaman Hidroponik Menggunakan Selenoid Valve Berbasis Mikrokontroller. Yogyakarta.Universitas PGRI Yogyakarta.

[4] Buti Delya, Ahmad Tusi dkk.2014. Jurnal Teknik Pertanian Lampung Vol.3, No.3: 205-212 Rancang Bangun Sistem Hidroponik Pasang Surut Otomatis Untuk Budidaya Tanaman Cabai.Lampung.Universitas Lampung.

[5] Dani Tri Pamularso.2014.Pengendali Alat Elektronik Berbasis Arduino Menggunakan Sensor Suhu.Malang.Universitas Muhammadiyah Malang.

[6] Fatehul Amir, Diana Rahmawati dkk.2017. Penyiram Tanaman Berbasis Telepon Seluluer Pintar dan Jaringan Sensor Fuzzy Tanpa Kabel.Surabaya: Universitas Airlangga,Seminar Nasional Matematika dan Aplikasinya.

[7] Happy Nugrahaning Widhi dkk.2014. Gema Teknologi vol. 18 No. 1 Sistem Penyiram Tanaman Anggrek Menggunkaan Sensor Kelembaban Dengan Program Borland Delphi \& Berbasis Modul Arduino R3.Semarang.Universitas Diponegoro.

[8] Singgih Atmadilaga.2016.Pengembangan Smart Farming Sistem Penyiraman Tanaman Hidroponik dan Akuaponik.Bandung.Universitas Pasundan Bandung.

[10] Wahyu Adi Prayitno, Adharul Muttaqin dkk.2017. Jurnal Pengembangan Teknologi Informasi dan Ilmu Komputer Vol. 1, No. 4 Sistem Monitoring Suhu, Kelembaban, dan Pengendali Penyiraman Tanaman Hidroponik menggunakan Blynk Android.Malang.Universitas Brawijaya.

[11] Widiharto.2017.Sistem Penyiram Tanaman Yang Dapat di Monitor dengan Komputer dan Perangkat Mobile.Surakarta.Universitas Muhammadiyah. 